\title{
IEDITORIAL
}

\section{A positive cumulative fluid balance in critically ill patients: is it really harm for everybody?}

\author{
Yoav Bichovsky, Moti Klein, Evgeni Brotfain \\ Department of Anesthesiology and Critical Care, General Intensive Care Unit, Soroka Medical Center, Ben-Gurion University of the Negev, Beer-Sheva, Israel
}

\section{RELATED ARTICLE} by Trejnowska et al, see p. 1147

Correspondence to: Evgeni Brotfain, MD, Department of Anesthesiology and Critical Care, Soroka Medical Center, Ben-Gurion University of the Negev, 151 Rager St., 85025 Beer-Sheva, Israel, phone: +972 546218106, email: bem1975@gmail.com Received: October 16, 2019. Accepted: October 17, 2019. Published online: December 19, 2019. Kardiol Pol. 2019; 77 (12): 1121-1122 doi:10.33963/KP.15111 Copyright by the Author(s), 2019
Fluid therapy in the intensive care unit (ICU) remains controversial and creates a difficult dilemma. The rationale for fluid administration in sepsis and trauma is based on the presence of primary or secondary hypovolemia due to volume loss, severe vasodilation, capillary leak, and third-space losses. ${ }^{1,2}$ The main aim of early fluid treatment is to achieve an acceptable volemic state (central venous pressure, 8-10 mm $\mathrm{Hg}$ for nonventilated persons). Thus, early aggressive fluid resuscitation has resulted in a significant improvement in clinical outcome of critically ill patients with sepsis and trauma. ${ }^{1,2}$ Therefore, it is not surprising that a very large positive fluid balance (FB) is a common finding in this population.

However, this statement is not true for everyone. Even slight cumulative positive FB may in itself be harmful and can worsen respiratory function, ${ }^{3,4}$ associated with increased mortality in patients with acute renal failure $e^{4-7}$ and cardiac in critically ill subpopulations. ${ }^{7-10}$

On the same topic, in the current issue of Kardiologia Polska (Kardiol Pol, Polish Heart Journal), Trejnowska et $a l^{11}$ published a retrospective, observational survey of the importance of positive FB in critically ill patients. The study was conducted between January 2012 to December 2016 in 2 ICUs of Silesian Center for Heart Disease in Poland, including a total of 495 patients admitted to both ICUs. The overwhelming majority of them were patients with cardiovascular and respiratory compromise. The authors found a strong correlation between $\mathrm{cu}^{-}$ mulative positive FB and increased mortality in cardiac critically ill patients. ${ }^{11}$ The predominance of critically ill patients with cardiovascular disorders in the present study is very important in that the significance of fluid management is different for cardiac and noncardiac critically ill subpopulations..$^{7-10}$ The adequacy and appropriateness of fluid therapy (crystalloids and colloids) for cardiac patients is highly debatable, and it is suggested that more vasopressors, inotropes, and mechanical support should be used instead. ${ }^{12}$ From this point of view, the significance of positive FB in critically ill patients could not be judged by this highly selected population in which most patients suffered from cardiovascular disease as a cause of the ICU treatment. It is also worth mentioning that the authors did not present data on catecholamine administration, acute renal and respiratory dysfunction, and other types of shock.

Trejnowska et a ${ }^{11}$ highlighted in their study that even a minor quantity of positive FB might be associated with an increased risk of death in cardiac critically ill patients. Those findings are in line with a previous paper by Boyd et al, ${ }^{13}$ who also demonstrated that a more positive FB (more than 3 liters at 12 hours), both early in resuscitation and cumulatively over 4 days, was associated with an increased risk of mortality in septic shock. Trejnowska et $\mathrm{al}^{11}$ reported that the main difference in cumulative positive daily FB between survivors and nonsurvivors was about 1 liter of fluids during the first 72 hours of the ICU stay (see Figure 1 in the original paper). This is a small positive FB that might be considered negligible and might not require resuscitation in patients with trauma and sepsis but might be detrimental for those with significant cardiovascular and respiratory compromise.

\section{ARTICLE INFORMATION}

DISCLAIMER The opinions expressed by the author are not necessarily those of the journal editors, Polish Cardiac Society, or publisher.

CONFLICT OF INTEREST None declared. 
OPEN ACCESS This is an Open Access article distributed under the terms of the Creative Commons Attribution-NonCommercial-NoDerivatives $4.0 \mathrm{In}$ ternational License (CC BY-NC-ND 4.0), allowing third parties to download articles and share them with others, provided the original work is properly cited, not changed in any way, distributed under the same license, and used for noncommercial purposes only. For commercial use, please contact the journal office at kardiologiapolska@ptkardio.pl.

HOW TO CITE Bichovsky Y, Klein M, Brotfain E. A positive cumulative fluid balance in critically ill patients: is it really harm for everybody? Kardiol Pol. 2019; 77: 1121-1122. doi:10.33963/KP.15111

\section{REFERENCES}

1 Gutierrez G, Reines HD, Wulf-Gutierrez ME. Clinical review: hemorrhagic shock. Crit Care. 2004; 8: 373-381.

2 Singer M, Deutschman CS, Seymour CW, et al. The third international consensus definitions for sepsis and septic shock (Sepsis-3). JAMA. 2016; 315: 801-810.

3 Sakr Y, Vincent JL, Reinhart K, et al. High tidal volume and positive fluid balance are associated with worse outcome in acute lung injury. Chest. 2005; 128: 3098-3108.

4 Upadya A, Tilluckdharry L, Muralidharan V, et al. Fluid balance and weaning outcomes. Intensive Care Med. 2005; 31: 1643-1647.

5 Payen $D$, de Pont AC, Sakr Y, et al. A positive fluid balance is associated with a worse outcome in patients with acute renal failure. Crit Care. 2008; 12: R74.

6 Campbell AJ, Cook JA, Adey G, Cuthbertson BH. Predicting death and readmission after intensive care discharge. Br J Anaesth. 2008; 100: 656-662.

7 Durbin CG Jr, Kopel RF. A case-control study of patients readmitted to the intensive care unit. Crit Care Med. 1993; 21: 1547-1553.

8 Abulebda K, Cvijanovich NZ, Thomas N], et al. Post-ICU admission fluid balance and pediatric septic shock outcomes: a risk-stratified analysis. Crit Care Med. 2014; 42: 397-403.

9 Pradeep A, Rajagopalam S, Kolli HK. et al. High volumes of intravenous fluid during cardiac surgery are associated with increased mortality. HSR Proc Intensive Care Cardiovasc Anesth. 2010; 2: 287-296.

10 Haase-Fielitz A, Haase M, Bellomo R, et al. Perioperative hemodynamic instability and fluid overload are associated with increasing acute kidney injury severity and worse outcome after cardiac surgery. Blood Purif. 2017; 43: 298-308.

11 Trejnowska E, Skoczyński S, Armatowicz P, et al. The importance of fluid balance in critically ill patients: a retrospective observational study. Kardiol Pol. 2019; 77: 1147-1154.

12 Thiele H, Ohman EM, de Waha-Thiele S, et al. Management of cardiogenic shock complicating myocardial infarction: an update 2019. Eur Heart J. 2019; 40: 2671-2683.

13 Boyd JH, Forbes J, Nakada TA, et al. Fluid resuscitation in septic shock: A positive fluid balance and elevated central venous pressure are associated with increased mortality. Crit Care Med. 2011; 39: 259-265. 